\title{
Impact of Surgical Resection on Metachronous Metastases of Colorectal Cancer According to Tumor Doubling Time
}

\author{
HIROAKI MIYAKE ${ }^{1}$, KOJI MURONO ${ }^{1}$, KAZUSHIGE KAWAI ${ }^{1}$, HIROAKI NOZAWA ${ }^{1}$, \\ HARUFUMI MAKI ${ }^{2}$, KIYOSHI HASEGAWA ${ }^{2}$, JUN NAKAJIMA ${ }^{3}$ and SOICHIRO ISHIHARA ${ }^{1}$ \\ ${ }^{1}$ Department of Surgical Oncology, The University of Tokyo, Tokyo, Japan; \\ ${ }^{2}$ Hepato-Biliary-Pancreatic Surgery Division, Artificial Organ and Transplantation Division, \\ Department of Surgery, Graduate School of Medicine, The University of Tokyo, Tokyo, Japan; \\ ${ }^{3}$ Department of Thoracic Surgery, The University of Tokyo, Tokyo, Japan
}

\begin{abstract}
Background/Aim: We aimed to elucidate the prognostic impact of tumor doubling time (DT) and radical surgery when classified by DT in patients with metachronous liver, lung, or peritoneal metastases of colorectal cancer (CRC). Patients and Methods: We reviewed the data of 1941 patients who underwent curative surgery for CRC and calculated DT for recurrences using computed tomography. Results: Short DT was an independent prognostic risk factor in liver $(p<0.001)$ and peritoneal $(p=0.03)$ metastases. Survival was significantly better in patients who underwent surgery than in those who did not, both in short and long DT groups in any metastatic organ $(p<0.01)$. Patients with long DT gained significantly better prognostic benefit from surgery than those with short $D T$ in liver $(p=0.01)$ and peritoneal $(p=0.04)$ metastases. Conclusion: Surgery is recommended for resectable metastases, especially in patients with liver and peritoneal metastases with long DT.
\end{abstract}

The liver, lung, and peritoneum are the most frequent metastatic sites in colorectal cancer (CRC), and there is a consensus that radical surgery improves the prognosis of metastases in the liver $(1,2)$, lung $(2,3)$, and peritoneum (48). However, patients with metastases of CRC sometimes experience early recurrence and poor prognosis despite

This article is freely accessible online.

Correspondence to: Hiroaki Miyake, MD, Department of Surgical Oncology, The University of Tokyo, 7-3-1 Hongo, Bunkyo-ku, Tokyo 113-8655, Japan. Tel: +81 9091317248 (mobile), +81 338155411 (ext. 33246) (office), Fax: +81 338116822, e-mail: MIYAKEH-SUR@h.u-tokyo.ac.jp

Key Words: Colorectal carcinoma, doubling time, prognosis, recurrence, tumor growth rate. radical surgery. Therefore, the decision to operate high-risk patients must be taken carefully.

The tumor growth rate may influence the tumor recurrence rate. Tumor doubling time (DT) has been used as an indicator of the tumor growth rate. DT is the time taken for a tumor to double in volume, and was first proposed by Collins (9, 10). Previously, in some studies, short DT was reported as an independent risk factor for poor prognosis in liver (11-14), lung $(15,16)$, and peritoneal (17) metastases of CRC. However, these studies included only patients who underwent radical surgery for metastases. No studies have been conducted on all recurrent patients including patients treated non-operatively. Therefore, it is unclear whether the prognosis is improved by radical surgery when stratified according to short and long DT groups.

Here, we aimed to elucidate the prognostic impact of DT and radical surgery in all patients with metachronous liver, lung, or peritoneal metastases of CRC.

\section{Patients and Methods}

Patient selection. Between January 2004 and December 2015, a total of 1,941 consecutive patients who underwent curative surgery for stage I-IV CRC at The University of Tokyo Hospital were retrospectively evaluated. Patients with inflammatory bowel diseaseassociated CRC and familial adenomatous polyposis were excluded. We analyzed prognosis in patients with metachronous liver, lung, and peritoneal metastases. DT was not considered when deciding on the treatment method for patients with metachronous metastases. The protocol was approved by the Ethics Committee of The University of Tokyo. The approval number was 3252-(9).

Patient follow-up. Postoperative surveillance was performed according to the surveillance schedule recommended by the Japanese Society for Cancer of the Colon and Rectum guidelines (18). Carcinoembryonic antigen (CEA) measurement, computed tomography (CT), and colonoscopy were performed every 3,6 , and 12 months, respectively for 3 years, followed by CEA measurement and $\mathrm{CT}$ every 6 months during the next 2 years. 
Table I. Patient characteristics.

\begin{tabular}{|c|c|c|c|c|c|}
\hline \multirow[t]{2}{*}{ Characteristics } & & \multirow{2}{*}{$\begin{array}{l}\text { Total } \\
1941\end{array}$} & \multicolumn{3}{|c|}{ Patients with metachronous metastasis } \\
\hline & & & $\begin{array}{l}\text { Liver } \\
212\end{array}$ & $\begin{array}{l}\text { Lung } \\
156\end{array}$ & $\begin{array}{c}\text { Peritoneal } \\
114\end{array}$ \\
\hline \multirow[t]{2}{*}{ Gender } & Male & $1181(60.8 \%)$ & $131(61.8 \%)$ & $88(56.4 \%)$ & $75(65.8 \%)$ \\
\hline & Female & $760(39.2 \%)$ & $81(38.2 \%)$ & $68(43.6 \%)$ & $39(34.2 \%$ \\
\hline Age, mean \pm SD & & $65.6 \pm 11.5$ & $64.4 \pm 11.2$ & $63.4 \pm 12.5$ & $63.2 \pm 10.9$ \\
\hline \multicolumn{6}{|l|}{ Primary lesion } \\
\hline \multirow[t]{2}{*}{ Location } & Colon & $1150(59.2 \%)$ & $125(59.0 \%)$ & $54(34.6 \%)$ & $49(43.0 \%)$ \\
\hline & Rectum & $791(40.8 \%)$ & $87(41.0 \%)$ & $102(65.4 \%)$ & $65(57.0 \%)$ \\
\hline \multirow[t]{2}{*}{ Histology } & Differentiated & $1830(94.3 \%)$ & $198(93.4 \%)$ & $147(94.2 \%)$ & $101(88.6 \%)$ \\
\hline & Other & $111(5.7 \%)$ & $14(6.6 \%)$ & $9(5.8 \%)$ & $13(11.4 \%)$ \\
\hline \multirow[t]{2}{*}{ Vascular invasion } & Absent & $676(34.8 \%)$ & $29(13.7 \%)$ & $30(19.2 \%)$ & $16(14.0 \%)$ \\
\hline & Present & $1265(65.2 \%)$ & $183(86.3 \%)$ & $126(80.8 \%)$ & $98(86.0 \%)$ \\
\hline \multirow[t]{2}{*}{ Lymphatic invasion } & Absent & $1396(71.9 \%)$ & $115(54.2 \%)$ & $87(55.8 \%)$ & $56(49.1 \%)$ \\
\hline & Present & $545(28.1 \%)$ & $97(45.8 \%)$ & $69(44.2 \%)$ & $58(50.9 \%)$ \\
\hline \multirow[t]{2}{*}{ T stage } & $\mathrm{T} 1-3$ & $1570(80.9 \%)$ & $138(65.1 \%)$ & $112(71.8 \%)$ & $54(47.4 \%)$ \\
\hline & $\mathrm{T} 4$ & $371(19.1 \%)$ & $74(34.9 \%)$ & $44(28.2 \%)$ & $60(52.6 \%)$ \\
\hline \multirow[t]{2}{*}{$\mathrm{N}$ stage } & No & $1186(61.1 \%)$ & $67(31.6 \%)$ & $61(39.1 \%)$ & $36(31.6 \%)$ \\
\hline & $\mathrm{N} 1-2$ & $755(38.9 \%)$ & $145(68.4 \%)$ & $95(60.9 \%)$ & $78(68.4 \%)$ \\
\hline \multirow[t]{2}{*}{ Examined lymph nodes } & $0-11$ & $486(25.0 \%)$ & $34(16.0 \%)$ & $41(26.3 \%)$ & $26(22.8 \%)$ \\
\hline & $\geq 12$ & $1455(75.0 \%)$ & $178(84.0 \%)$ & $115(73.7 \%)$ & $88(77.2 \%)$ \\
\hline \multirow[t]{4}{*}{ pStage } & I & $523(26.9 \%)$ & $10(4.7 \%)$ & $9(5.8 \%)$ & $2(1.8 \%)$ \\
\hline & II & $627(32.3 \%)$ & $37(17.5 \%)$ & $37(23.7 \%)$ & $27(23.7 \%)$ \\
\hline & III & $624(32.1 \%)$ & $86(40.6 \%)$ & $65(41.7 \%)$ & $50(43.9 \%)$ \\
\hline & IV & $167(8.6 \%)$ & $79(37.3 \%)$ & $45(28.8 \%)$ & $35(30.7 \%)$ \\
\hline \multirow[t]{2}{*}{ Serum CEA level } & $\leq 5.0 \mathrm{ng} / \mathrm{ml}$ & $1120(57.7 \%)$ & $80(37.7 \%)$ & $70(44.9 \%)$ & $45(39.5 \%)$ \\
\hline & $>5.0 \mathrm{ng} / \mathrm{ml}$ & $821(42.3 \%)$ & $132(62.3 \%)$ & $86(55.1 \%)$ & $69(60.5 \%)$ \\
\hline \multirow[t]{2}{*}{ Adjuvant chemotherapy } & Absent & $1317(67.9 \%)$ & $121(57.1 \%)$ & $79(50.6 \%)$ & $51(44.7 \%)$ \\
\hline & Present & $624(32.1 \%)$ & $91(42.9 \%)$ & $77(49.4 \%)$ & $63(55.3 \%)$ \\
\hline Follow-up, median (range) & & 5.0 year $(0.1-14.8)$ & & & \\
\hline \multicolumn{6}{|l|}{ Metachronous lesion } \\
\hline \multirow[t]{2}{*}{ Concurrent metastases } & Absent & & $144(67.9 \%)$ & $91(58.3 \%)$ & $72(63.2 \%)$ \\
\hline & Present & & $68(32.1 \%)$ & $65(41.7 \%)$ & $42(36.8 \%)$ \\
\hline \multirow[t]{3}{*}{ Disease free interval ${ }^{\mathrm{a}}$} & $\leq 1$ year & & $138(65.1 \%)$ & $87(55.8 \%)$ & $49(43.0 \%)$ \\
\hline & $1-3$ year & & $63(29.7 \%)$ & $58(37.2 \%)$ & $52(45.6 \%)$ \\
\hline & $>3$ year & & $11(5.2 \%)$ & $11(7.1 \%)$ & $13(11.4 \%)$ \\
\hline \multirow[t]{5}{*}{ Treatment } & Resection & & $141(66.5 \%)$ & $70(44.9 \%)$ & $38(33.3 \%)$ \\
\hline & Conversion & & $6(2.8 \%)$ & $4(2.6 \%)$ & $2(1.8 \%)$ \\
\hline & Chemotherapy & & $48(22.6 \%)$ & $61(39.1 \%)$ & $53(46.5 \%)$ \\
\hline & Radiotherapy & & $0(0 \%)$ & $3(1.9 \%)$ & $2(1.8 \%)$ \\
\hline & Best supportive care & & $17(8.0 \%)$ & $18(11.5 \%)$ & $19(16.7 \%)$ \\
\hline \multirow[t]{3}{*}{ DT, median (range) days } & & & $32(5-319)$ & $66(6-249)$ & $87(12-523)$ \\
\hline & DT with surgery & & $39(10-319)$ & $85(18-249)$ & $120(30-523)$ \\
\hline & DT without surgery & & $24(5-120)$ & $58(6-248)$ & $56(12-213)$ \\
\hline \multirow[t]{3}{*}{ PCI at recurrence } & Low $(<10)$ & & & & $99(86.8 \%)$ \\
\hline & Moderate (10-20) & & & & $15(13.2 \%)$ \\
\hline & High $(>20)$ & & & & $0(0 \%)$ \\
\hline
\end{tabular}

aTime interval from the date of surgery for the primary lesion to the date of clinical diagnosis of metachronous metastasis. CEA: Carcinoembryonic antigen; DT: doubling time; SD: standard deviation; PCI: peritoneal cancer index.

Measurements of DT. DT was calculated according to a previously described method $(17,19)$. Briefly, DT was mainly calculated from the tumor diameter measured by CT (slice thickness: $5.0 \mathrm{~mm}$ ) twice during the radiotherapy- and chemotherapy-free interval. When the lesion was too small to determine whether it was a recurrence, we evaluated it using CT again 1-3 months later and diagnosed it as recurrence in case of an increase in size. In other cases, when the small sized recurrent lesions were detected in $\mathrm{CT}$ before the diagnosis of recurrence in a retrospective evaluation, we calculated DT immediately. Cases where obtaining accurate measurements of the tumor diameter was difficult or when CT was performed only once were excluded from the evaluation of DT. 
Miyake et al: CRC Prognosis Based on Doubling Time

Table II. Univariate and multivariate analyses of risk factors of overall survival after metachronous liver metastases of CRC.

\begin{tabular}{|c|c|c|c|c|}
\hline \multirow[t]{2}{*}{ Factors } & \multicolumn{2}{|c|}{ Univariate } & \multicolumn{2}{|c|}{ Multivariate } \\
\hline & $\mathrm{HR}(95 \% \mathrm{CI})$ & $p$-Value & HR $(95 \% \mathrm{CI})$ & $p$-Value \\
\hline Gender (Male/Female) & $1.09(0.73-1.64)$ & 0.67 & & \\
\hline Age $(\leq 65 />65$ years $)$ & $0.93(0.63-1.38)$ & 0.73 & & \\
\hline \multicolumn{5}{|l|}{ Primary lesion } \\
\hline Site (Colon/Rectum) & $1.23(0.83-1.85)$ & 0.32 & & \\
\hline Histology (Other/Differentiated) & $2.69(1.26-5.07)$ & 0.01 & $1.70(0.69-3.60)$ & 0.23 \\
\hline Vascular Invasion $(+/-)$ & $2.15(1.11-4.81)$ & 0.02 & $2.00(0.91-5.28)$ & 0.09 \\
\hline Lymph invasion $(+/-)$ & $2.35(1.58-3.51)$ & $<0.001$ & $1.34(0.86-2.11)$ & 0.2 \\
\hline Tumor stage (T4/T1-3) & $1.33(0.89-1.97)$ & 0.16 & & \\
\hline $\mathrm{N}$ stage $(\mathrm{N} 1-2 / \mathrm{N} 0)$ & $1.44(0.94-2.26)$ & 0.09 & & \\
\hline Examined LN $(0-11 / \geq 12)$ & $1.11(0.64-1.82)$ & 0.7 & & \\
\hline Distant metastasis $(+/-)$ & $1.29(0.86-1.91)$ & 0.21 & & \\
\hline CEA level $(>5.0 / \leq 5.0 \mathrm{ng} / \mathrm{ml})$ & $1.28(0.86-1.94)$ & 0.23 & & \\
\hline Adjuvant chemotherapy (+/-) & $0.85(0.57-1.26)$ & 0.41 & & \\
\hline \multicolumn{5}{|l|}{ Metachronous lesion } \\
\hline Liver DT ( $\leq 45 />45$ days) & $5.43(3.06-10.5)$ & $<0.001$ & $3.44(1.87-6.84)$ & $<0.001$ \\
\hline Concurrent metastases $(+/-)$ & $2.97(2.00-4.42)$ & $<0.001$ & $1.37(0.85-2.19)$ & 0.2 \\
\hline Resection $(-/+)$ & $9.19(5.89-14.4)$ & $<0.001$ & $4.74(2.79-8.08)$ & $<0.001$ \\
\hline
\end{tabular}

CEA: Carcinoembryonic antigen; CI: confidence interval; CRC: colorectal cancer; DT: doubling time; HR: hazard ratio; LN: lymph node.

DT cut-off values. Patients with metachronous metastases were stratified into two groups according to DT in each recurrent organ; short and long DT groups. The cut-off values for liver, lung, and peritoneal metastases were determined as 45,100 , and 137 days, respectively, according to previously reported median values $(16,17,20)$.

Statistical analyses. In this study, we analyzed survival after recurrence, which was defined as the interval between the diagnosis of metachronous metastases and the last follow-up or death. Overall survival (OS) rates were calculated by the Kaplan-Meier method and compared using the log-rank test. To compare the effect of surgical resection in short and long DT groups, the analysis of interaction test was used. Cox proportional hazards univariate and multivariate models were constructed to detect risk factors for OS. The factors analyzed included sex, age, primary site of tumor, histology, vascular/lymph invasion, tumor stage, number of examined lymph nodes, $\mathrm{N}$ stage, presence of distant metastasis, CEA level, administration of adjuvant chemotherapy, DT for metachronous lesion, concurrent metastases at other sites, resection of metachronous lesion, and the peritoneal cancer index in cases of metachronous peritoneal metastasis. In the multivariate analysis, the variables with $p<0.05$ from the univariate analysis were included. We considered $p$-values $<0.05$ to be statistically significant. All data were analyzed statistically using JMP Pro 14 (SAS Institute Inc., Cary, NC, USA).

\section{Results}

Patient characteristics. Patient characteristics are summarized in Table I. The average ( \pm standard deviation) age was $66( \pm 11.5)$ years. The median follow-up time was
5.0 years (range $=0.1-14.8$ years). Of all 1,941 patients who underwent curative surgery for stage I-IV CRC, recurrences were detected in 466 patients $(24.0 \%)$. Among the recurrent organs, the liver was most commonly involved $(n=212)$, followed by the lung $(n=156)$ and peritoneum $(n=114)$, and DT could be calculated in 191, 127, and 90 patients, respectively. The median DT for recurrences in the liver, lung, and peritoneum were 32 (range=5-319), 66 (range=6249 ), and 87 (range=12-523) days, respectively. The median DT was the shortest in the liver, followed by the lung and peritoneum $(p<0.001)$. In patients who underwent surgical resection, the median DT for recurrences in the liver, lung, and peritoneum was 39 (range $=10-319), 85($ range $=18-249)$, and 120 (range $=30-523$ ) days, respectively and in patients treated non-operatively, these were 24 (range=5-120), 58 (range $=6-248)$, and 56 (range $=12-213$ ) days, respectively. The resection rate of the recurrent organs was the highest for the liver $(69.3 \%)$, followed by the lung (47.5\%) and peritoneum $(35.1 \%)$.

Risk factors for OS after metachronous metastases. These data are summarized in Tables II, III, and IV. In the univariate analysis, short DT was a significant risk factor for poor OS in any organ (liver, lung, and peritoneum). In the multivariate analysis, short DT was an independent risk factor for poor OS in the liver [hazard ratio $(\mathrm{HR})=3.44,95 \%$ confidence interval $(\mathrm{CI})=1.87-6.84 ; p<0.001]$ and peritoneum $(\mathrm{HR}=2.53,95 \% \mathrm{CI}=1.09-6.96 ; p=0.03)$. Moreover, not operating in patients with metachronous metastases was an 
Table III. Univariate and multivariate analyses of risk factors of overall survival after metachronous lung metastases of CRC.

\begin{tabular}{|c|c|c|c|c|}
\hline \multirow[t]{2}{*}{ Factors } & \multicolumn{2}{|c|}{ Univariate } & \multicolumn{2}{|c|}{ Multivariate } \\
\hline & $\mathrm{HR}(95 \% \mathrm{CI})$ & $p$-Value & $\mathrm{HR}(95 \% \mathrm{CI})$ & $p$-Value \\
\hline Gender (Male/Female) & $1.04(0.65-1.68)$ & 0.87 & & \\
\hline Age $(\leq 65 />65$ years $)$ & $0.55(0.34-0.88)$ & 0.01 & $0.59(0.31-1.08)$ & 0.09 \\
\hline \multicolumn{5}{|l|}{ Primary lesion } \\
\hline Site (Colon/Rectum) & $1.41(0.87-2.27)$ & 0.16 & & \\
\hline Histology (Other/Differentiated) & $2.63(1.01-5.60)$ & 0.047 & $1.52(0.23-5.86)$ & 0.61 \\
\hline Vascular Invasion $(+/-)$ & $1.40(0.78-2.73)$ & 0.28 & & \\
\hline Lymph invasion $(+/-)$ & $1.72(1.07-2.77)$ & 0.03 & $0.95(0.46-2.02)$ & 0.9 \\
\hline Tumor stage (T4/T1-3) & $1.49(0.88-2.45)$ & 0.13 & & \\
\hline $\mathrm{N}$ stage $(\mathrm{N} 1-2 / \mathrm{N} 0)$ & $2.14(1.30-3.66)$ & 0.003 & $1.76(0.83-3.70)$ & 0.14 \\
\hline Examined LN $(0-11 / \geq 12)$ & $0.67(0.37-1.14)$ & 0.14 & & \\
\hline Distant metastasis $(+/-)$ & $1.43(0.87-2.32)$ & 0.16 & & \\
\hline CEA level $(>5.0 / \leq 5.0 \mathrm{ng} / \mathrm{ml})$ & $1.01(0.63-1.62)$ & 0.96 & & \\
\hline Adjuvant chemotherapy $(+/-)$ & $0.99(0.61-1.59)$ & 0.96 & & \\
\hline \multicolumn{5}{|l|}{ Metachronous lesion } \\
\hline Lung DT ( $\leq 100 />100$ days) & $4.09(1.78-11.8)$ & $<0.001$ & $2.16(0.88-6.52)$ & 0.1 \\
\hline Concurrent metastases $(+/-)$ & $2.95(1.83-4.81)$ & $<0.001$ & $1.88(1.04-3.46)$ & 0.04 \\
\hline Resection $(-/+)$ & $8.44(4.65-16.5)$ & $<0.001$ & $5.72(2.84-12.4)$ & $<0.001$ \\
\hline
\end{tabular}

CEA: Carcinoembryonic antigen; CI: confidence interval; CRC: colorectal cancer; DT: doubling time; HR: hazard ratio; LN: lymph node.

independent risk factor for poor OS in the liver $(\mathrm{HR}=4.74$, $95 \% \mathrm{CI}=2.79-8.08 ; p<0.001)$, lung $(\mathrm{HR}=5.72,95 \% \mathrm{CI}=2.84-$ $12.4 ; p<0.001)$, and peritoneum $(\mathrm{HR}=7.34,95 \% \mathrm{CI}=3.17-$ $19.1 ; p<0.001)$.

Patient prognosis. In patients with liver, lung, and peritoneal metastases, the 5-year OS rates after metachronous metastases were $51.9 \%, 47.0 \%$, and $13.7 \%$, respectively, and the median OS time was 5.4, 4.9, and 2.3 years, respectively. OS after metachronous metastases according to DT are shown in Figure 1. The prognosis in patients with short DT was significantly worse than that in patients with long DT in any organ. The 5year OS rates in patients with short and long DT were $37.0 \%$ and $84.4 \%$ in liver metastasis $(p<0.001), 41.3 \%$ and $91.5 \%$ in lung metastasis $(p=0.001)$, and $3.2 \%$ and $67.9 \%$ in peritoneal metastasis $(p<0.001)$, respectively.

Survival curves according to DT and surgical resection are shown in Figure 2. In patients with metachronous liver, lung, and peritoneal metastases, the 5-year OS rates in those who underwent radical surgery were $92.1 \%, 96.3 \%$, and $88.9 \%$ in the long DT group and $53.0 \%, 71.1 \%$, and $11.8 \%$ in the short DT group, respectively. OS was significantly better in patients who underwent radical surgery than in those who did not, both in short and long DT groups in liver $(p<0.001$ and $p<0.001$, respectively), lung $(p<0.001$ and $p=0.001$, respectively), and peritoneal $(p<0.001$ and $p<0.001$, respectively) metastases, respectively.

In patients with long DT, the HRs for not undergoing versus undergoing surgical resection were 29.5, 8.12, and 50.6 for metastases in the liver, lung, and peritoneum, respectively. These HRs were higher than those in patients with short DT for metastases in the liver $(\mathrm{HR}=29.5$ vs. 5.38 , $95 \% \mathrm{CI}=8.95-97.4$ vs. 3.31-8.75) and peritoneum $(\mathrm{HR}=50.6$ vs. $6.20,95 \% \mathrm{CI}=5.41-473$ vs. $2.80-13.8)$. The analysis of the interaction test showed that patients with long DT gained significantly better prognostic benefit from surgical resection than those with short DT in liver $(p=0.01)$ and peritoneal $(p=0.04)$ metastases. No significant difference between the two groups was observed for cases with lung metastasis $(p=0.80)$.

\section{Discussion}

This is the first study to evaluate the impact of DT as a predictive factor for prognosis in all patients with metachronous metastases of $\mathrm{CRC}$, including both patients who underwent radical surgery and those treated nonoperatively. Short DT has previously been described as an independent risk factor for poor OS and relapse-free survival (RFS) among patients who underwent radical surgery for liver (11) and peritoneal (17) metastases. These results are consistent with our present study. In lung metastasis, the association between DT and prognosis was shown by evaluating RFS $(15,16)$, but not OS. In our present study concerning lung metastasis, HR for short versus long DT, suggested a lower OS for patients with short DT, but the difference was not statistically significant $(\mathrm{HR}=2.16$, $95 \% \mathrm{CI}=0.88-6.52 ; p=0.10)$. Further studies are needed to identify the association between DT and the prognosis for lung metastasis. 
Miyake et al: CRC Prognosis Based on Doubling Time

Table IV. Univariate and multivariate analyses of risk factors of overall survival after metachronous peritoneal metastases of CRC.

\begin{tabular}{|c|c|c|c|c|}
\hline \multirow[t]{2}{*}{ Factors } & \multicolumn{2}{|c|}{ Univariate } & \multicolumn{2}{|c|}{ Multivariate } \\
\hline & HR $(95 \% \mathrm{CI})$ & $p$-Value & HR (95\%CI) & $p$-Value \\
\hline Gender (Male/Female) & $0.78(0.49-1.28)$ & 0.33 & & \\
\hline Age $(\leq 65 />65$ years $)$ & $0.64(0.40-1.01)$ & 0.06 & & \\
\hline \multicolumn{5}{|l|}{ Primary lesion } \\
\hline Site (Colon/Rectum) & $1.72(1.09-2.72)$ & 0.02 & $1.30(0.74-2.32)$ & 0.37 \\
\hline Histology (Other/Differentiated) & $3.59(1.76-6.71)$ & 0.001 & $2.46(1.07-5.26)$ & 0.03 \\
\hline Vascular Invasion (+/-) & $1.37(0.74-2.85)$ & 0.34 & & \\
\hline Lymph invasion $(+/-)$ & $1.78(1.14-2.81)$ & 0.01 & $1.09(0.57-2.08)$ & 0.79 \\
\hline Tumor stage (T4/T1-3) & $1.37(0.88-2.16)$ & 0.16 & & \\
\hline $\mathrm{N}$ stage $(\mathrm{N} 1-2 / \mathrm{N} 0)$ & $2.26(1.36-3.92)$ & 0.001 & $3.25(1.58-7.08)$ & 0.001 \\
\hline Examined LN $(0-11 / \geq 12)$ & $1.05(0.62-1.70)$ & 0.86 & & \\
\hline Distant metastasis $(+/-)$ & $1.15(0.70-1.85)$ & 0.58 & & \\
\hline CEA level $(>5.0 / \leq 5.0 \mathrm{ng} / \mathrm{ml})$ & $1.04(0.65-1.64)$ & 0.86 & & \\
\hline Adjuvant chemotherapy (+/-) & $1.52(0.95-2.44)$ & 0.08 & & \\
\hline \multicolumn{5}{|l|}{ Metachronous lesion } \\
\hline Peritoneal DT ( $\leq 137 />137$ days $)$ & $5.13(2.36-13.5)$ & $<0.001$ & $2.53(1.09-6.96)$ & 0.03 \\
\hline PCI $(\geq 10 /<10)$ & $3.28(1.64-6.10)$ & 0.001 & $2.47(1.06-5.44)$ & 0.04 \\
\hline Concurrent metastases (+/-) & $1.64(1.04-2.56)$ & 0.03 & $1.29(0.69-2.40)$ & 0.43 \\
\hline Resection $(-/+)$ & $10.0(5.21-21.3)$ & $<0.001$ & $7.34(3.17-19.1)$ & $<0.001$ \\
\hline
\end{tabular}

CEA: Carcinoembryonic antigen; CI: confidence interval; CRC: colorectal cancer; DT: doubling time; HR: hazard ratio; LN: lymph node; PCI: peritoneal cancer index.

OS rates were significantly better in patients who underwent radical surgery than in those who did not, both in short and long DT groups for any metastatic lesion. In previous studies, the prognosis in patients with metastases of CRC was improved by surgical resection in the liver $(1,2)$, lung $(2,3)$, and peritoneum (4-8). Therefore, surgical resection is recommended in the Japanese guidelines for the treatment of CRC (18). Our finding that surgical resection was beneficial regardless of the length of DT supports this idea. Moreover, the analysis of the interaction test showed that the impact of surgical resection was significantly higher in patients with long DT than in those with short DT in liver and peritoneal metastases. Therefore, patients with long DT were considered better candidates for surgical resection of liver and peritoneal metastases than those with short DT. In patients with short DT, the 5-year OS rates in those who underwent radical surgery were $53.0 \%$ and $71.1 \%$ in liver and lung metastases, respectively; however, most patients with peritoneal metastasis who underwent radical surgery died within 5 years. In addition, surgical resection for metastatic lesions can be sometimes invasive. Therefore, the decision on surgical resection for peritoneal metastasis with short DT should be made carefully.

The median DT in our study was shorter than that reported in previous studies $(16,17,20)$, which maybe because of the difference in the inclusion criteria. While previous studies were designed only for those patients who underwent radical surgery for metastases, our study was designed for all recurrent patients including those who underwent radical surgery and those treated non-operatively. In the present study, DT in patients treated nonoperatively was shorter than that in patients who underwent surgical resection. DT in patients who underwent surgical resection was consistent with that reported in previous studies. The tumor progression in patients with short DT was considered rapid and unresectable. The prognosis in patients who underwent radical surgery was significantly better than that in patients treated non-operatively even in the short DT group. Therefore, it is important to detect recurrences at an early stage before they become unresectable through surveillance after surgical resection. There are conflicting reports about whether intensive surveillance improves the patient's OS (21-24) or not (25-29). Surveillance schedule in Japan (18) is more intensive than that in Europe and the United States (30-32). Because tumors with short DT are associated with low surgical resection rates, intensive surveillance may improve the prognosis in the short DT group. A large-sized prospective study that evaluates not only the prognosis but also the radiation exposure from the use of CT and the cost of medical care is necessary to propose an optimal surveillance schedule.

This study has several limitations. First, due to its retrospective nature, prospective studies are needed to verify whether surgical resection for metastases really improves prognosis. Second, the number of patients treated nonoperatively in the long DT group was small, restricting the ability to demonstrate that the effect of surgical resection of lung metastasis was better in the long than in the short DT group. Third, definitive cut-off values for DT remain unclear. 
a) Liver metastasis

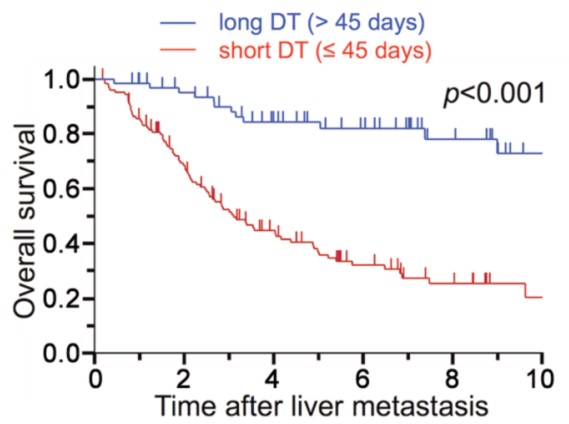

Number at risk

(Years)

- $\begin{array}{lllllllllll}65 & 61 & 56 & 49 & 41 & 36 & 32 & 26 & 19 & 14 & 10\end{array}$

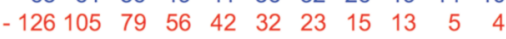

\section{b) Lung metastasis}

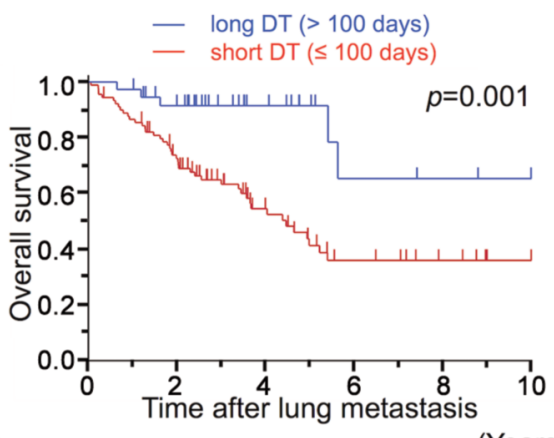

Number at risk c) Peritoneal metastasis

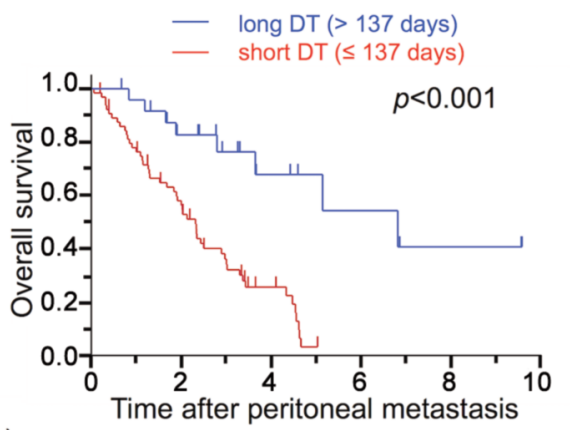

Number at risk

(Years)

- $\begin{array}{lllllllllll}37 & 36 & 29 & 19 & 14 & 9 & 5 & 5 & 4 & 3 & 2\end{array}$

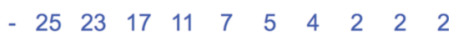

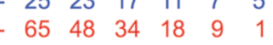

Figure 1. Overall survival curves after metachronous a) liver, b) lung, and c) peritoneal metastases of CRC according to DT. CRC: Colorectal cancer; DT: doubling time.

\section{a) Liver metastasis}

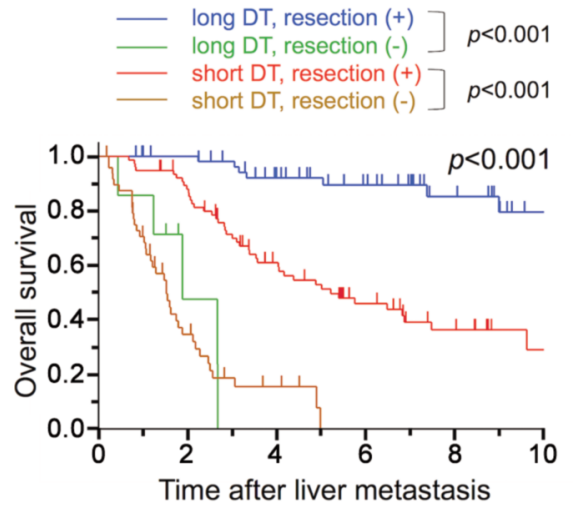

Number at risk b) Lung metastasis

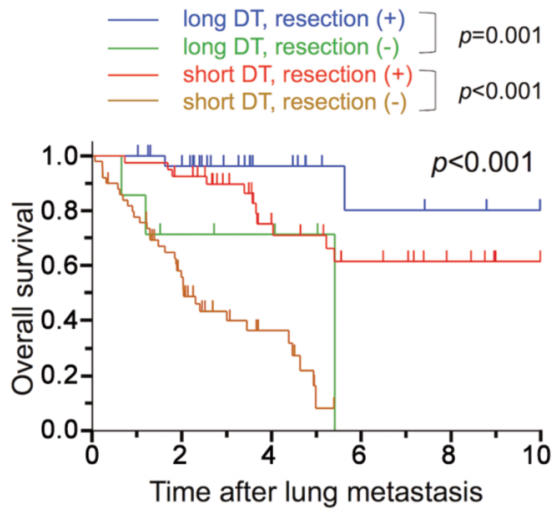

(Years)

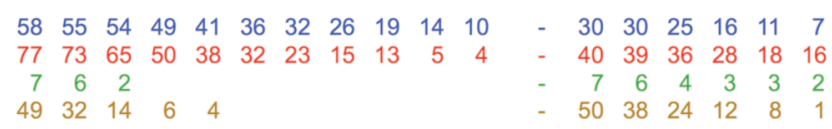

Number at risk

(Years)

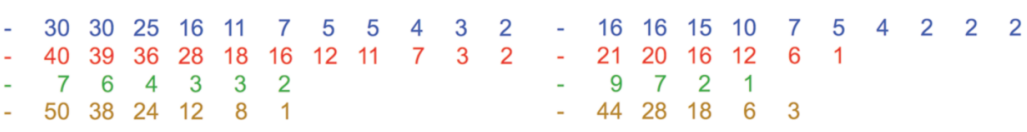

c) Peritoneal metastasis

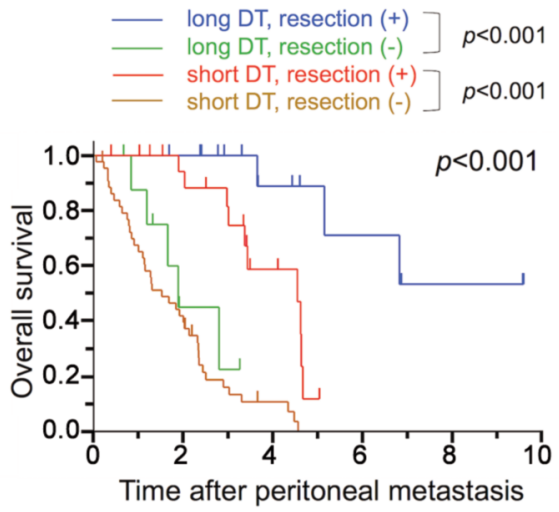

(Years)

Figure 2. Overall survival curves after metachronous a) liver, b) lung, and c) peritoneal metastases of CRC according to DT and surgical resection. CRC: Colorectal cancer; DT: doubling time.

Although we determined the cut-off values according to previous studies to compare our data with them, further validation is needed to establish the best cut-off values.

In conclusion, short DT was shown to be an independent risk factor for poor OS in patients with metachronous liver and peritoneal metastases of CRC. Surgical resection is recommended for resectable metastatic lesions to improve the prognosis of patients with metachronous metastases regardless of the length of DT. Especially, patients with long DT were shown to be better candidates for surgical resection of liver and peritoneal metastases than those with short DT. However, the decision on intensive surgical resection for peritoneal metastasis with short DT should be carefully considered.

\section{Funding}

The study was partly supported from the Japan Agency for Medical Research and Development (grant number: JP19cm0106502) and 
from the Japan Society for the Promotion of Science (grant numbers: 19K09115, 19K09114, 18K07194, 17K10623, 17K10621, and 17K10620).

\section{Conflicts of Interest}

There are no conflicts of interest to declare regarding this study.

\section{Authors' Contributions}

Hiroaki Miyake acquired the data, established the study design and concept, analyzed the data, and drafted the article. Koji Murono interpreted the data and revised the article. Kazushige Kawai acquired the data and revised the article. Soichiro Ishihara, Hiroaki Nozawa, Harufumi Maki, Kiyoshi Hasegawa, and Jun Nakajima revised the article. All Authors have approved the final version of the manuscript.

\section{Acknowledgements}

The Authors thank Editage (https://www.editage.jp/) for the English language review.

\section{References}

1 Abdalla EK, Vauthey JN, Ellis LM, Ellis V, Pollock R, Broglio $\mathrm{KR}$, Hess K and Curley SA: Recurrence and outcomes following hepatic resection, radiofrequency ablation, and combined resection/ablation for colorectal liver metastases. Ann Surg 239(6): 818-827, 2004. PMID: 15166961. DOI: 10.1097/01.sla. 0000128305.90650 .71

2 Luo D, Liu Q, Yu W, Ma Y, Zhu J, Lian P, Cai S, Li Q and Li $\mathrm{X}$ : Prognostic value of distant metastasis sites and surgery in stage iv colorectal cancer: A population-based study. Int J Colorectal Dis 33(9): 1241-1249, 2018. PMID: 29931408. DOI: 10.1007/s00384-018-3091-x

3 Ike H, Shimada H, Ohki S, Togo S, Yamaguchi S and Ichikawa Y: Results of aggressive resection of lung metastases from colorectal carcinoma detected by intensive follow-up. Dis Colon Rectum 45(4): 468-475, 2002. PMID: 12006927. DOI: 10.1007/ s10350-004-6222-0

4 Shida D, Yoshida T, Tanabe T, Tsukamoto S, Ochiai H and Kanemitsu Y: Prognostic impact of R0 resection and targeted therapy for colorectal cancer with synchronous peritoneal metastasis. Ann Surg Oncol 25(6): 1646-1653, 2018. PMID: 29572704. DOI: $10.1245 / \mathrm{s} 10434-018-6436-3$

5 Shida D, Tsukamoto S, Ochiai H and Kanemitsu Y: Long-term outcomes after R0 resection of synchronous peritoneal metastasis from colorectal cancer without cytoreductive surgery or hyperthermic intraperitoneal chemotherapy. Ann Surg Oncol 25(1): 173-178, 2018. PMID: 29063295. DOI: 10.1245/s10434017-6133-7

6 Nagata H, Ishihara S, Hata K, Murono K, Kaneko M, Yasuda K, Otani K, Nishikawa T, Tanaka T, Kiyomatsu T, Kawai K, Nozawa $\mathrm{H}$ and Watanabe T: Survival and prognostic factors for metachronous peritoneal metastasis in patients with colon cancer. Ann Surg Oncol 24(5): 1269-1280, 2017. PMID: 27995451. DOI: 10.1245/s10434-016-5732-z

7 Abdel-Rahman O: A real-world, population-based study of the outcomes of patients with metastatic colorectal cancer to the peritoneum treated with or without cytoreductive surgery. Int J Colorectal Dis 35(4): 719-725, 2020. PMID: 32060606. DOI: 10.1007/s00384-020-03525-x

8 Imaizumi K, Nishizawa Y, Ikeda K, Tsukada Y, Sasaki T and Ito M: Prognostic impact of curative resection for peritoneal recurrence of colorectal cancer. Ann Surg Oncol 27(7): $2487-$ 2497, 2020. PMID: 32052301. DOI: 10.1245/s10434-02008242-x

9 Collins VP, Loeffler RK and Tivey H: Observations on growth rates of human tumors. Am J Roentgenol Radium Ther Nucl Med 76(5): 988-1000, 1956. PMID: 13362715.

10 Collins VP: Time of occurrence of pulmonary metastasis from carcinoma of colon and rectum. Cancer 15: 387-395, 1962. PMID: 13880612. DOI: 10.1002/1097-0142(196203/04)15: $2<387:$ :aid-cncr2820150222>3.0.co;2-5

11 Tanaka K, Shimada H, Fujii Y, Endo I, Sekido H, Togo S and Ike $\mathrm{H}$ : Pre-hepatectomy prognostic staging to determine treatment strategy for colorectal cancer metastases to the liver. Langenbecks Arch Surg 389(5): 371-379, 2004. PMID: 15605168. DOI: 10.1007/s00423-004-0490-y

12 Tanaka K, Shimada H, Ueda M, Matsuo K, Endo I and Togo S: Long-term characteristics of 5-year survivors after liver resection for colorectal metastases. Ann Surg Oncol 14(4): 1336-1346, 2007. PMID: 17235718. DOI: 10.1245/s10434-006-9071-3

13 Nomura K, Miyagawa S, Harada H, Kitamura H, Seki H, Shimada R, Kobayashi A, Noike $\mathrm{T}$ and Kawasaki S: Relationship between doubling time of liver metastases from colorectal carcinoma and residual primary cancer. Dig Surg 15(1): 21-24, 1998. PMID: 9845558. DOI: 10.1159/000018581

14 Kito A, Tanaka K, Fujimaki H, Nakazawa M, Togo S, Minami $\mathrm{M}$ and Shimada H: Tumor doubling time and local immune response to hepatic metastases from colorectal cancer. J Surg Oncol 96(6): 525-533, 2007. PMID: 17654526. DOI: 10.1002/ jso.20806

15 Kawaguchi K, Uehara K, Nakayama G, Fukui T, Fukumoto K, Nakamura S and Yokoi K: Growth rate of chemotherapy-naive lung metastasis from colorectal cancer could be a predictor of early relapse after lung resection. Int J Clin Oncol 21(2): 329334, 2016. PMID: 26280748. DOI: 10.1007/s10147-015-0889-1

16 Tomimaru Y, Noura S, Ohue M, Okami J, Oda K, Higashiyama M, Yamada T, Miyashiro I, Ohigashi H, Yano M, Kodama K, Ishikawa O, Murata K, Yokouchi H, Sasaki Y, Kameyama M and Imaoka S: Metastatic tumor doubling time is an independent predictor of intrapulmonary recurrence after pulmonary resection of solitary pulmonary metastasis from colorectal cancer. Dig Surg 25(3): 220-225, 2008. PMID: 18577868. DOI: 10.1159/ 000140693

17 Miyake H, Murono K, Nagata H, Nozawa H, Kawai K, Hata K, Tanaka T, Nishikawa T, Shuno Y, Sasaki K and Ishihara S: Prognostic significance of doubling time in patients undergoing radical surgery for metachronous peritoneal metastases of colorectal cancer. Int J Colorectal Dis 34(5): 801-809, 2019. PMID: 30739186. DOI: 10.1007/s00384-019-03259-5

18 Watanabe T, Muro K, Ajioka Y, Hashiguchi Y, Ito Y, Saito Y, Hamaguchi T, Ishida H, Ishiguro M, Ishihara S, Kanemitsu Y, Kawano H, Kinugasa Y, Kokudo N, Murofushi K, Nakajima T, Oka S, Sakai Y, Tsuji A, Uehara K, Ueno H, Yamazaki K, Yoshida M, Yoshino T, Boku N, Fujimori T, Itabashi M, Koinuma N, Morita T, Nishimura G, Sakata Y, Shimada Y, Takahashi K, Tanaka S, Tsuruta O, Yamaguchi T, Yamaguchi N, 
Tanaka T, Kotake K, Sugihara K and Japanese Society for Cancer of the Colon and Rectum: Japanese society for cancer of the colon and rectum (JSCCR) guidelines 2016 for the treatment of colorectal cancer. Int J Clin Oncol 23(1): 1-34, 2018. PMID: 28349281. DOI: $10.1007 / \mathrm{s} 10147-017-1101-6$

19 Schwartz M: A biomathematical approach to clinical tumor growth. Cancer 14: 1272-1294, 1961. PMID: 13909709. DOI: 10.1002/1097-0142(196111/12)14:6<1272::aid-cncr 2820140618>3.0.co;2-h

20 Tanaka K, Shimada H, Miura M, Fujii Y, Yamaguchi S, Endo I, Sekido $\mathrm{H}$, Togo $\mathrm{S}$ and Ike H: Metastatic tumor doubling time: most important prehepatectomy predictor of survival and nonrecurrence of hepatic colorectal cancer metastasis. World J Surg 28(3): 263-270, 2004. PMID: 14961200. DOI: 10.1007/ s00268-003-7088-3

21 Pita-Fernandez S, Alhayek-Ai M, Gonzalez-Martin C, LopezCalvino B, Seoane-Pillado $\mathrm{T}$ and Pertega-Diaz S: Intensive follow-up strategies improve outcomes in nonmetastatic colorectal cancer patients after curative surgery: A systematic review and meta-analysis. Ann Oncol 26(4): 644-656, 2015. PMID: 25411419. DOI: 10.1093/annonc/mdu543

22 Zhao Y, Yi C, Zhang Y, Fang F and Faramand A: Intensive follow-up strategies after radical surgery for nonmetastatic colorectal cancer: A systematic review and meta-analysis of randomized controlled trials. PLoS One 14(7): e0220533, 2019. PMID: 31361784. DOI: 10.1371/journal.pone.0220533

23 Tjandra JJ and Chan MK: Follow-up after curative resection of colorectal cancer: A meta-analysis. Dis Colon Rectum 50(11): 1783-1799, 2007. PMID: 17874269. DOI: 10.1007/s10350-0079030-5

24 Renehan AG, Egger M, Saunders MP and O'Dwyer ST: Impact on survival of intensive follow up after curative resection for colorectal cancer: systematic review and meta-analysis of randomised trials. BMJ 324(7341): 813, 2002. PMID: 11934773. DOI: $10.1136 / \mathrm{bmj} .324 .7341 .813$

25 Wille-Jorgensen P, Syk I, Smedh K, Laurberg S, Nielsen DT, Petersen SH, Renehan AG, Horvath-Puho E, Pahlman L, Sorensen HT and Group CS: Effect of more vs. less frequent follow-up testing on overall and colorectal cancer-specific mortality in patients with stage II or III colorectal cancer: the COLOFOL randomized clinical trial. JAMA 319(20): 20952103, 2018. PMID: 29800179. DOI: 10.1001/jama.2018.5623

26 Snyder RA, Hu CY, Cuddy A, Francescatti AB, Schumacher JR, Van Loon K, You YN, Kozower BD, Greenberg CC, Schrag D, Venook A, McKellar D, Winchester DP, Chang GJ and Alliance for Clinical Trials in Oncology Network Cancer Surveillance Optimization Working G: Association between intensity of posttreatment surveillance testing and detection of recurrence in patients with colorectal cancer. JAMA 319(20): 2104-2115, 2018. PMID: 29800181. DOI: 10.1001/jama.2018.5816
27 Primrose JN, Perera R, Gray A, Rose P, Fuller A, Corkhill A, George S, Mant D and Investigators FT: Effect of 3 to 5 years of scheduled cea and CT follow-up to detect recurrence of colorectal cancer: the FACS randomized clinical trial. JAMA 311(3): 263-270, 2014. PMID: 24430319. DOI: 10.1001/jama. 2013.285718

28 Mant D, Gray A, Pugh S, Campbell H, George S, Fuller A, Shinkins B, Corkhill A, Mellor J, Dixon E, Little L, PereraSalazar R and Primrose J: A randomised controlled trial to assess the cost-effectiveness of intensive versus no scheduled followup in patients who have undergone resection for colorectal cancer with curative intent. Health Technol Assess 21(32): 1-86, 2017. PMID: 28641703. DOI: 10.3310/hta21320

29 Rosati G, Ambrosini G, Barni S, Andreoni B, Corradini G, Luchena G, Daniele B, Gaion F, Oliverio G, Duro M, Martignoni G, Pinna N, Sozzi P, Pancera G, Solina G, Pavia G, Pignata S, Johnson F, Labianca R, Apolone G, Zaniboni A, Monteforte M, Negri E, Torri V, Mosconi P, Fossati R and group Gw: A randomized trial of intensive versus minimal surveillance of patients with resected Dukes B2-C colorectal carcinoma. Ann Oncol 27(2): 274-280, 2016. PMID: 26578734. DOI: $10.1093 /$ annonc/mdv541

30 National Comprehensive Cancer Network: NCCN clinical practice guidelines in oncology-colon cancer, version 2. 2019. Available at: https://www.nccn.org/professionals/physician_gls/ pdf/colon.pdf [Last accessed Dec 15, 2019]

31 Steele SR, Chang GJ, Hendren S, Weiser M, Irani J, Buie WD, Rafferty JF, Clinical Practice Guidelines Committee of the American Society of Colon and Rectal Surgeons: Practice guideline for the surveillance of patients after curative treatment of colon and rectal cancer. Dis Colon Rectum 58(8): 713-725, 2015. PMID: 26163950. DOI: 10.1097/DCR.0000000000000410

32 Labianca R, Nordlinger B, Beretta GD, Mosconi S, Mandala M, Cervantes A, Arnold D and ESMO Guidelines Working Group: Early colon cancer: ESMO clinical practice guidelines for diagnosis, treatment and follow-up. Ann Oncol 24(6): vi64-72, 2013. PMID: 24078664. DOI: $10.1093 /$ annonc/mdt354 